\title{
Tuberculose vertebral (doença de Pott) associada a abscesso de psoas: relato de dois casos e revisão da literatura
}

\author{
Spinal tuberculosis (Pott's disease) associated to psoas abscess: report of \\ two cases and a literature review
}

\author{
Fernando Crivelenti Vilar¹, Fábio Fernandes Neves², Jeová Keny Baima Colares ${ }^{1}$ \\ e Benedito Antônio Lopes da Fonseca ${ }^{1}$
}

\begin{abstract}
RESUMO
A tuberculose é uma das principais doenças infecciosas de acometimento mundial com 3,9 milhões de casos notificados no mundo, em 2002. A forma esquelética pode corresponder a 3\% do número total de casos, sendo 50\% devido à tuberculose vertebral. 0 abscesso de psoas é uma entidade clínica rara com aproximadamente 12 casos relatados por ano na literatura médica e tem no Mycobacterium tuberculosis, um dos seus agentes etiológicos. $O$ objetivo deste trabalho é relatar dois casos de tuberculose vertebral associada a abscesso de psoas atendidos em nosso serviço, bem como uma revisão da literatura.
\end{abstract}

Palavras-chaves: doença de Pott. Tuberculose vertebral. Mycobacterium tuberculosis. Abscesso de psoas.

\begin{abstract}
Tuberculosis is one of the most important infectious disease worldwide, with 3,9 million reported cases in the world in 2002. The skeletal form is responsible for $3 \%$ of the total number of cases, with $50 \%$ of these due to spinal tuberculosis. The psoas abscess is a rare clinical entity with approximately 12 cases per year described in the medical literature and has in the Mycobacterium tuberculosis, one of its etiologic agents. The objective of this work is to report two cases of spinal tuberculosis associated with psoas abscess attended at our service, as well as a review of the literature.
\end{abstract}

Key-words: Pott's disease. Spinal tuberculosis. Mycobacterium tuberculosis. Psoas abscess.

A tuberculose é uma das principais causas de morte entre as doenças infecciosas, com cerca de 1,8 milhões de óbitos anuais, segundo a Organização Mundial de Saúde. Em 2002, estimou-se a ocorrência de 8,8 milhões de novos casos de tuberculose, sendo $40 \%$ desses, formas pulmonares baciliferas ${ }^{26}$. No Brasil, em 2001, ocorreram 5.421 óbitos em decorrência da tuberculose $\mathrm{e}^{17}$. Dentre as diversas formas da doença, a músculoesquelética corresponde a até 3\%, sendo a tuberculose vertebral responsável pela metade dos casos ${ }^{25}$. As complicações neurológicas associadas a esta forma da tuberculose são responsáveis pela alta morbidade desta doença ${ }^{21}$.

Esta forma de apresentação da tuberculose foi descrita inicialmente em 1779 por Percival Pott, que determinou a utilidade da drenagem de abscessos frios no tratamento da paraplegia decorrente do acometimento vertebral ${ }^{22}$.
A tuberculose vertebral, também denominada doença de Pott, era muito mais comum na era pré-antibiótica, quando o tratamento preconizado para tuberculose constava de ar fresco, repouso e boa nutrição.

0 local mais acometido é a coluna torácica, seguida da coluna lombossacra e cervical com, respectivamente, $50 \%$, $40 \%$ e $10 \%$ dos casos ${ }^{19}$.

0 abscesso de psoas, apesar de raro, é uma patologia infecciosa importante devido a potencial ameaça à vida. Sua incidência foi estimada em aproximadamente 12 casos por ano no mundo em 1992. Esses números têm aumentado devido à melhoria das técnicas de imagem para detecção (antes da TC, $70 \%$ dos diagnósticos eram feitos em necropsia) e pelo aumento da incidência de tuberculose em países desenvolvidos ${ }^{20}$. No Brasil, não há dados a respeito de sua incidência.

\footnotetext{
1. Divisão de Moléstias Infecciosas do Departamento de Clínica Médica da Faculdade de Medicina de Ribeirão Preto da Universidade de São Paulo, Ribeirão Preto, SP. 2. Unidade de Emergência do Hospital das Clínicas da Faculdade de Medicina de Ribeirão Preto da Universidade de São Paulo, Ribeirão Preto, SP.

Endereço para correspondência: Prof. Benedito Antonio Lopes da Fonseca. Depto de Clínica Médica HC/FMRP/USP. Av. Bandeirantes 3900, Campus Universitário, 14048-900 Ribeirão Preto, SP. e-mail: baldfons@fmrp.usp.br Recebido para publicação em 24/1/2005 Aceito em 31/3/2006
} 


\section{RELATO DOS CASOS}

Caso 1. Paciente de 29 anos, sexo feminino, branca, do lar, natural e procedente de Ribeirão Preto, SP. Relatava surgimento de tumoração na coluna há 3 meses. Queixavase de dor local importante, que irradiava para membros inferiores. Apresentava febre vespertina ocasional há 6 meses. Perdeu 3 quilos no período. Tosse seca esporádica, principalmente noturna. Negava etilismo, contato com pacientes portadores de tuberculose ou co-morbidades.

Achados clínicos. Apresentava-se bastante emagrecida, sendo evidenciado abaulamento ao nível da transição toracolombar, indolor e sem sinais flogísticos. Ausência de déficits neurológicos em membros inferiores. Presença de vários gânglios axilares, inguinais e cervicais, pequenos, móveis, fibroelásticos e indolores.

Exames complementares. A radiografia simples de tórax e coluna mostrou velamento retículo-nodular difuso à direita e fratura em corpos vertebrais de T11 e T12. A tomografia computadorizada (TC) mostrou corpos vertebrais de T10, T11 e T12 com redução da altura e várias áreas de destruição óssea. 0 processo extendia-se para psoas esquerdo, com área hipodensa medindo $12 \times 4 \times 3 \mathrm{~cm}$, com reforço pós-contraste. 0 ELISA para tuberculose foi positivo (Relação D.0./cut-off: 1,17) e a reação cutânea à tuberculina mostrou halo de $18 \mathrm{~mm}$ após 72 horas. ELISA anti-HIV negativo. A análise histopatológica do material obtido por biópsia incisional evidenciou osteomielite crônica exudativa, com extensas áreas de necrose. Pesquisa de bacilos álcoolácido resistentes (BAAR) negativa na coloração de ZiehlNeelsen. A cultura para micobactérias foi positiva, com isolamento de Mycobacterium tuberculosis.

Evolução clínica. Foi submetida à cirurgia ortopédica com enxerto de osso ilíaco e tratada com esquema I do Ministério da Saúde para tuberculose, com boa evolução quanto à marcha $\mathrm{e}$ mobilidade lombar, relatando apenas dor local ocasional.

Caso 2. Paciente de 33 anos, sexo masculino, mulato, trabalhador braçal, natural de Arapongas, PR e procedente de Santa Rosa do Viterbo, SP. Relatava estalo em região de coluna lombar, durante exercício profissional, apresentando dor lombar súbita, que irradiava para coxa direita há 18 meses. Evoluiu com paraparesia progressiva.

o quadro melhorava parcialmente com antiinflamatórios. Informava também febre esporádica, uma vez por semana, que baixava com dipirona. Perdeu $8 \mathrm{~kg}$ no período. Etilismo social. Um companheiro de serviço era portador de tuberculose pulmonar, mas o contato era ocasional. Apresentou pneumonia há 2 anos, que durou 2 meses e foi de resolução espontânea.

Achados clínicos. Observado edema ao nível de L2-L3, porém sem dor à palpação. Apresentava paraparesia.

Exames complementares. Tórax radiologicamente normal. Na radiografia de coluna, observava-se irregularidade de contornos das placas terminais de L2 e L3 e acentuada redução do espaço discal correspondente. $\mathrm{Na}$ tomografia computadorizada de coluna evidenciaram-se lesões osteolíticas bem definidas, com contornos regulares e reforço irregular após contraste. Extensão do processo para interior do canal vertebral (L2-L3) e para musculatura paravertebral com imagem sugestiva de abscesso, medindo $18 \times 6 \times 6 \mathrm{~cm}$ em psoas esquerdo (Figura 1). A ressonância nuclear magnética (RNM) evidenciou ainda adenomegalia retro-peritonial. A análise histológica de biópsia incisional revelou processo inflamatório crônico granulomatoso, com células gigantes multinucleadas e necrose caseosa. Não foram evidenciados BAAR na coloração de Ziehl-Neelsen. O ELISA para tuberculose foi positivo (Relação D.0./cut-off: 1,45). ELISA anti-HIV negativo. A cultura e a reação em cadeia da polimerase (PCR) para micobactérias no fragmento ósseo foram negativas.

Evolução clínica. Foi submetido à cirurgia ortopédica para debridamento e drenagem de psoas, bem como prescrito o esquema I para tratamento de tuberculose, recebendo alta do Ambulatório de Infectologia, apresentando recuperação total da marcha.
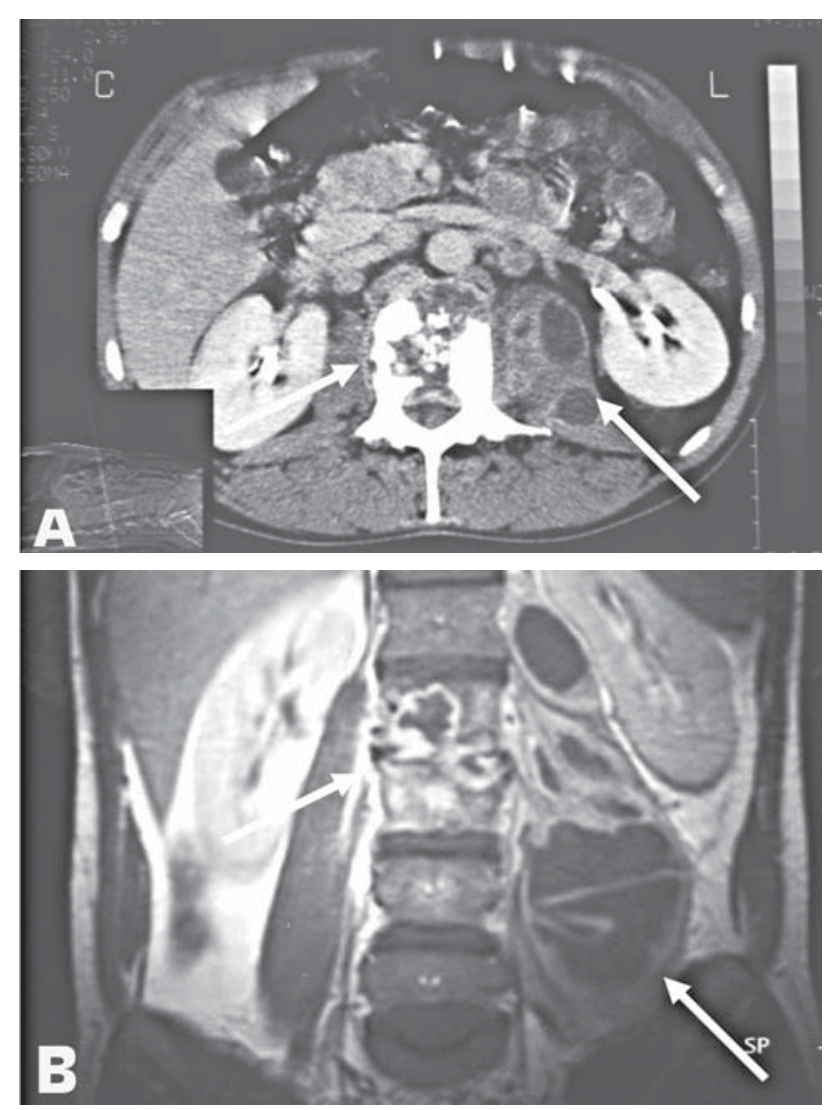

Figura 1 - A: TC mostrando corte longitudinal na altura de $\mathrm{L3}$ com destruição do corpo vertebral bem como abscesso de músculo psoas à esquerda. B: RNM mostrando corte transversal, deixando claro o acometimento vertebral e de psoas.

\section{DISCUSSÃO E REVISÃO DA LITERATURA}

A disseminação esquelética da tuberculose é muito mais comum em pacientes HIV-positivos ${ }^{3}$, chegando a $60 \%$ dos $\operatorname{casos}^{18}$, devido à imunossupressão associada a esses indivíduos que permite uma disseminação da infecção pelo Mycobacterium tuberculosis e aumento na incidência de 
tuberculose extrapulmonar?. Entretanto, seu diagnóstico é dificultado nestes pacientes, pois coexiste em meio a outras artrites infecciosas, doenças reumatológicas e medulares, espondilites, que neles incidem com maior frequiência ${ }^{11}{ }^{12}$.

Três tipos de envolvimento vertebral são relatados: paradiscal, anterior ou central. 0 primeiro é responsável por mais da metade dos casos, onde o microorganismo se implanta na metáfise vertebral, erodindo a lâmina terminal, levando ao estreitamento do espaço discal. No acometimento anterior, a lesão ocorre abaixo do ligamento longitudinal anterior, elevando o periósteo e causando desvascularização. Esse processo é responsável pela formação de necrose óssea e abscessos. A lesão central é a pior, visto que acomete toda a vértebra, levando mais freqüentemente à instabilidade da coluna ${ }^{2}$.

A deformidade cifótica ocorre devido ao colapso das estruturas vertebrais anteriores. A perda de um corpo vertebral pode levar a $30-35^{\circ}$ de desvio na coluna. Curvaturas maiores que estas evoluem com colapso da coluna em cerca de $90 \%$ dos casos, num período de até 18 meses $^{23}$. Nos casos descritos nessa revisão, apenas no paciente 1 houve necessidade de intervenção cirúrgica com enxerto de ilíaco para que não ocorresse tal complicação. Já no paciente 2 , apesar de apresentar sintomatologia neurológica mais acentuada, o comprometimento ósseo não justificava tal conduta. 0 acometimento neurológico na Doença de Pott, que ocorre em 10 a 46\% dos pacientes, é determinado pela destruição óssea e/ou formação de abscessos frios, levando à compressão e inflamação medular ou das raízes, raramente acometendo tecido nervoso isoladamente ${ }^{110}$.

0 surgimento de abscessos paravertebrais na doença de Pott é comum. A coluna cervical é acometida mais frequientemente em crianças, sendo mais sintomático nessa faixa etária, pois geralmente ocorre compressão do esôfago e traquéia. No tórax, os abscessos podem invadir pulmões e pleura; na região lombar, disseminar inferiormente, através da bainha do psoas ou do trígono femoral e na região sacral, invadir o períneo ou glúteo através do forame isquiático maior ${ }^{12}$.

0 abscesso de psoas, em particular, é classificado em primário e secundário. 0 primário, provavelmente originário de disseminação hematogênica para o músculo, é mais comum em crianças e adultos menores de 30 anos, tendo no Staphylococcus aureus seu patógeno principal. Já o secundário, mais comum em adultos maiores de 50 anos, origina-se em sítios de infecção adjacentes, sendo o trato gastrintestinal (Escherichia coli e outras enterobactérias) e a coluna (Mycobacterium tuberculosis) os sítios primordiais de infecçã $0^{4}$.

O diagnóstico clínico da doença de Pott é pouco específico. Sua apresentação depende muito da idade do paciente, localização da infecção, estágio da doença e ausência ou presença de abscess $0^{12}$. Esse diagnóstico deve ser considerado na presença de sintomas sistêmicos como perda de peso, febre e astenia, com caráter evolutivo crônico ${ }^{2}$. A dor vertebral é de início insidioso, opondo-se à dor de início agudo de um abscesso piogênico ${ }^{12}$. 0 acometimento neurológico aumenta o grau de suspeita clínica. 0 hemograma apresenta-se usualmente normal, com velocidade de hemossedimentação aumentada e 0 teste cutâneo com injeção de tuberculina (PPD) positivo em $86 \%$ dos $\operatorname{casos}^{12}{ }^{13}$. Em pacientes HIV-positivos, o diagnóstico diferencial é mais abrangente, podendo representar outra infecção oportunista ou doença medular primária. Os exames complementares dependem do grau de imunodepressão, ocorrendo, por exemplo, anergia ao PPD em pacientes com imunodeficiência avançada ${ }^{11}$. A apresentação clínica dos casos relatados, ambos HIVnegativos, vai de encontro ao que é visto na literatura: nossos pacientes apresentaram sintomas sistêmicos crônicos (febre, perda de peso) além de dor vertebral com evolução insidiosa (três meses no caso 1 e dezoito meses no caso 2).

Os exames radiológicos podem mostrar níveis variados de deformidade óssea, diminuição do espaço intervertebral, deformidade cifótica e, frequientemente, abscessos frios nas adjacências. 0 paciente 1 apresentava redução da altura dos corpos vertebrais de T10 a T12 e abscesso de psoas esquerdo na TC. 0 paciente 2 apresentava redução do espaço discal de L2 - L3 e também abscesso de psoas esquerdo, evidenciados tanto na TC quanto na RNM (Figura 1), que mostrava ainda adenomegalia retroperitonial. A TC e a RNM são os exames de eleição para investigação diagnóstica. A primeira é mais acessível e quando mostra focos de calcificação dentro do abscesso é patognomônica de tuberculose e pode ainda guiar aspiração percutânea ${ }^{6}$, pois permite uma melhor visualização de tecido ósseo em relação a RNM.

0 melhor exame para o diagnóstico da doença de Pott é a biópsia guiada por TC, encaminhando-se material para estudos microbiológicos, moleculares (quando disponíveis) e anátomopatológicos 5 . 0 exame macroscópico mostra tecido amarelado, semelhante a queijo (caseum). Já a microscopia evidencia tecido de granulação, com formação de microabscessos. A presença de granuloma com necrose caseosa central e células gigantes do tipo Langherans são achados sugestivos, porém não patognomônicos de tuberculose vertebral ${ }^{2}$. A presença de BAAR auxilia no diagnóstico histopatológico, porém o diagnóstico de certeza é considerado quando há crescimento do Mycobacterium tuberculosis em cultura.

o ELISA, ensaio imuno-enzimático para detecção de anticorpos contra o Mycobacterium tuberculosis, depende do antígeno utilizado e da classe de imunoglobulinas procurada, possuindo valores de sensibilidade e de especificidade diferentes, dependendo do kit escolhido ${ }^{9} \mathrm{e}$ do tipo de amostra, sendo considerado método complementar. No caso da tuberculose vertebral, assim como em outras formas de tuberculose extrapulmonar, a sua relevância ao diagnóstico é limitada.

A PCR surgiu como importante ferramenta diagnóstica para os casos paucibacilares, possuindo grande especificidade (80 a 100\%) e boa sensibilidade (75\%) em formas extrapulmonares ${ }^{14}$. Porém, devido à possibilidade de falsos positivos e negativos, não se constitui em método diagnóstico definitivo, mantendo a demonstração do Mycobacterium tuberculosis em cultura o padrão ouro de diagnóstico.

Nos casos relatados, o paciente 1 teve seu diagnóstico confirmado através de cultura, com a demonstração do agente, não deixando dúvidas quanto à etiologia. Já no paciente 2, 
não houve crescimento do agente em culturas e a reação de PCR foi negativa. Entretanto a TC, o exame anátomopatológico do material e o ELISA para tuberculose sugeriam fortemente o diagnóstico. A prova terapêutica com esquema I para tuberculose, com boa evolução clínica, permitiu concluir que se tratava de um caso de tuberculose vertebral.

0 abscesso piogênico é o principal diagnóstico diferencial da Doença de Pott, apesar de cursar de forma mais aguda, sendo freqüente os sinais e sintomas de bacteremia. Outros diagnósticos diferenciais importantes são: actinomicose, nocardiose, sífilis terciária, micoses sistêmicas, brucelose e neoplasias metastáticas ${ }^{2}$, situações que foram excluídas na investigação dos pacientes descritos neste artigo.

A base da terapia para a doença de Pott é a quimioterapia antituberculosa com sucesso em mais de 90\% dos casos $^{24}$, deixando em segundo plano a abordagem cirúrgica, que possui indicações precisas e específicas.

o Ministério da Saúde do Brasil orienta que seja instituído o mesmo tratamento da tuberculose pulmonar, ou seja, rifampicina, isoniazida e pirazinamida por 2 meses, mantendose as duas primeiras por mais 4 meses (esquema I) ${ }^{16}$. Entretanto, alguns autores recomendam a adição de etambutol e/ou 0 prolongamento do tempo de tratamento para 9 ou até 12 meses $^{15}$.

A cirurgia pode ser indicada em 4 situações clínicas ${ }^{18}$ :

a) Aspiração ou drenagem cirúrgica dos abscessos frios paravertebrais que promove a regressão mais precoce do processo infeccioso, além de descomprimir estruturas nobres;

b) Debridamento mecânico do foco necrótico como uma técnica mais conservadora, atuando apenas nos tecidos necrosados. É preferível em relação às técnicas mais radicais, como a artrodese anterior;

c) Nos casos de paraplegia de curta evolução (menor que 6 meses), a descompressão das estruturas neurais e a estabilização da coluna vertebral podem promover recuperação dos déficits neurológicos. Nos casos de perda neurológica por processo vascular, o prognóstico é mais sombrio: pode ser tentado um curso de 3-4 semanas com tuberculostáticos, e indicar a cirurgia somente se não ocorrer melhora neurológica²; e

d) Nos casos de cifose com instabilidade da coluna vertebral, ou grande angulação, é indicada a fixação da coluna. Não é objetivo deste trabalho descrever técnicas e abordagens cirúrgicas.

Nos casos apresentados, duas técnicas foram utilizadas: no caso 1, pelo grau de comprometimento vertebral evidenciado nos exames radiológicos, foi feita descompressão de estruturas neurais com estabilização da coluna e enxerto de osso ilíaco. No caso 2, foi realizado apenas debridamento mecânico do foco necrótico para descomprimir estruturas nobres. O esquema I para tuberculose foi administrado corretamente nos dois casos, o que contribuiu de forma decisiva para a boa evolução clínica.

Diante da pandemia de tuberculose e do número crescente de pacientes imunodeprimidos (AIDS, transplantes, uso de imunodepressores e quimioterapia), fica cada dia mais comum o surgimento de formas extrapulmonares desta doença. A tuberculose vertebral bem como o abscesso de psoas devem estar presentes no diagnóstico diferencial de pacientes com dor lombar crônica, acompanhada de febre e síndrome consuptiva. Tão logo confirmado o diagnóstico, deve-se instituir o tratamento, pois dele resulta a boa evolução da doença, diminuindo a mortalidade e a gravidade das seqüelas neurológicas.

\section{REFERÊNCIAS BIBLIOGRÁFICAS}

1. Balbbuker SS, Tayede WB, Balbbuker SK. Atypical spinal tuberculosis. Journal of Bone and Joint Surgery 66B: 239-242, 1984.

2. Bachie-Adjei 0, Squillante RG. Tuberculosis of the Spine. Orthopedic Clinics of North America 27: 95-103, 1996.

3. Centers for Disease Control and Prevention. Expanded tuberculosis surveillance and tuberculosis morbidity. United States, 1993. Morbidity and Mortality WeeKly Report 43: 361-366, 1994.

4. Franco-Paredes E, Blumberg HM. Psoas Muscle Abscess Caused by Micobacterium tuberculosis and Staphylococcus aureus: Case Report and Review. The American Jounal of the Medical Sciences 321: 415 - 417, 2001.

5. Fyfe IS, Henry AP, Mulhulland RC. Closed vertebral biopsy. Journal of Bone and Joint Surgery 65B: 140-143, 1983.

6. Griffth JF, Kumta SM, Leung PC, Cheng JCY, Chow LTC, Metreweli C. Imaging of Musculoskeletal Tuberculosis: A New Look at an Old Disease. Clinical Orthopaedics and Related Research 398: 32-39, 2002.

7. Haas DW. Mycobacterium tuberculosis. In: Douglas M, Bennett's (eds) Principles and Practice of Infections Diseases, $5^{\text {th }}$ edtition, Churchill Livingstone, Chapter 240, 2000.

8. Hsu LCS, Leong JCY. Tuberculosis of the lower cervical spine. Journal of Bone and Joint Surgery 66B: 1-5, 1984.

9. Imaz MS, Comini MA, Zerbini E, Sequeira MD, Latini 0, Claus JD, Singh M. Evaluation of Commercial Enzyme-Linked Immunosorbent Assay Kits for Detection of Tuberculosis in Argentinean Population. Journal of Clinical Microbiology 42: 884-887, 2004.

10. Jain AK. Treatment of Tuberculosis of the Spine with Neurologic Complications Clinical Orthopaedics and Related Research 398: 75-84, 2002.

11. Jellis JE. Human Immunodeficiency Virus and Osteoarticular Tuberculosis. Clinical Orthopaedics and Related Research 398: 27-31, 2002.

12. Khoo LT, Mikawa K, Fessler G. A surgical revisitation of Pott distemper of the spine. The Spine Journal 3: 130-145, 2003

13. Lifeso RM, Weaver P, Harder EH. Tuberculosis espondilitis in adults. Journal of Bone and Joint Surgery 67A: 1405-1413, 1985.

14. Lodha R, Kabra SK. Newer diagnostic modalities for tuberculosis. Indian Journal of Pediatric 71: 221-227, 2004.

15. Medical research council working party on tuberculosis of spine. A 10year assessment of controlled trials of inpatient and outpatient treatment and of plaster of paris jackets for tuberculosis of the spine in children on standard chemotherapy: studies in Massan and Pusan, Korea. Journal of Bone and Joint Surgery 67: 103-110, 1985.

16. Ministério da Saúde. Manual de normas para o controle da tuberculose, Brasília, 1995.

17. Ministério da Saúde do Brasil/Fundação Nacional de Saúde/Centro Nacional de Epidemiologia, Brasil, 2001.

18. Moon MS. Tuberculosis of the spine: controversies and a new challenge. Spine 22: 1791-1797, 1997.

19. Moon MS, Ha KY et al. Pott's paraplegia - 67 cases. Clinical Orthopedics 323: 122-128, 1996.

20. Mückley T, Schütz T, Kirshner M, Potulski M, Hofmann G, Bühre Volker. Psoas Abscess: The Spine as Primary Source of Infection. Spine 28: E106E113, 2003. 
21. Pattison PRM. Pott's paraplegia: an account of the treatment of 89 consecutive patients. Parapleglia 24, 77-91, 1986.

22. Pott P. Remarks on that kind of palsy of the lower limbs which is frequently found to accompany curvature of the spine, and is supposed to be caused by it: together with its method of cure, to which added, observations on the necessity and property of amputations in certain circumstances. Medical classics, volume 1. MD Williams \& Wilkins, Baltimore, p.271-323, 1936
23. Rejasekaran S, Shanmugasundaram TK. Prediction of the gibbus deformity in tuberculosis of the spine. Journal of Bone and Joint Surgery 69A: 503 - 509, 1987.

24. Shembekar A, Badhulkar S. Chemotherapy for Osteoarticular Tuberculosis. Clinical Orthopaedics and Related Research 398: 20-26, 2002.

25. Tuli SM. General Principles of Osteoarticular Tuberculosis. Clinical Orthopaedics and Related Research 398: 11-19, 2002.

26. World Health Organization. Estimated tuberculosis incidence and mortality 2002. Annual report, 2002 